\title{
Resident Hospital Discharges by Severity of Illness at the Regional Level
}

\author{
Ronald Lagoe*, Gretchen Lagoe \\ Hospital Executive Council, Syracuse, NY, USA \\ Email: *Hospexcl@cnymail.com
}

How to cite this paper: Lagoe, R. and Lagoe, G. (2019) Resident Hospital Discharges by Severity of Illness at the Regional Level. Case Reports in Clinical Medicine, 8, 140-146.

https://doi.org/10.4236/crcm.2019.85016

Received: April 26, 2019

Accepted: May 27, 2019

Published: May 30, 2019

Copyright $\odot 2019$ by author(s) and Scientific Research Publishing Inc. This work is licensed under the Creative Commons Attribution International License (CC BY 4.0).

http://creativecommons.org/licenses/by/4.0/

(c) (i) Open Access

\begin{abstract}
In the twentieth century, government sponsored health planning focused on the use of services by population in the United States. This case study evaluated the impact of severity of illness for resident hospital discharges for 2017, the latest time period for which this information was available. It focused on the Central New York Health Service Area, one of the original health planning populations. The study demonstrated that patients at Extreme severity of illness constituted similar percentages of adult medicine and adult surgery populations in the Central New York Region. The sizes of Moderate severity of illness populations were also similar. The study identified considerable differences in the sizes of Minor and Major severity of illness populations for adult medicine and adult surgery in the Central New York Region. These differences resulted from large numbers of healthy patients in the adult surgery population. They were admitted for orthopedic procedures and procedures to address obesity.
\end{abstract}

\section{Keywords}

Hospitalization, Hospital Discharges, Severity of Illness

\section{Introduction}

In the United States and elsewhere, health care is closely associated with community and regional populations. The need for these services is generated by resident populations [1] [2].

Historically, health planning has focused on the utilization of services at regional and community levels. These initiatives have included the Health Systems Agencies developed by the federal government in the twentieth century, as well as State and local efforts to evaluate and regulate providers [3] [4].

These health planning programs focused on generating voluntary compliance 
from providers. Some of them were linked with payor approvals for specific projects, such as the Certificate of Need programs. They were administered by state or local planning staffs [3].

Most of these health planning programs were implemented before the use of current approaches to health care reimbursement and evaluation. They frequently employed relatively simple analytical tools, such as resource to population ratios.

Many of these programs phased out before the advent of more sophisticated approaches to hospital management. Reimbursement by discharge employing Diagnosis Related Groups was first implemented by Medicare in 1983. The evaluation of inpatient utilization by severity of illness began in the 1990s [5] [6] [7].

In the twenty first century, much of the attention concerning the use of health care has focused on provider utilization. Only recently interest in the connection between utilization and demographics has been renewed in population health [8] [9].

\section{Population}

This case study evaluated inpatient hospital utilization with respect to discharges and severity of illness in the Central New York Health Service Area. This region is one of the original health planning areas established by the federal health planning legislation of 1976. It includes eleven counties and a population of $1,124,173[10]$.

The Central New York Health Service Area is based on three groups of counties. The largest includes Onondaga County, where the City of Syracuse, the largest metropolitan area in the region, is located. Its demographics also include the Counties contiguous to Onondaga, Cayuga, Cortland, Madison, and Oswego Counties. They are populated by the suburbs of Syracuse, as well as numerous small towns and rural areas. Tompkins County, which includes the City of Ithaca, is located in the southern part of this area. Together, these six counties include a population of approximately, 698,830, or 62.1 percent of the regional total.

The northern part of the Central New York Health Service Area comprises Jefferson, St. Lawrence, and Lewis Counties. Jefferson County includes the City of Watertown, a number of small towns and rural areas, and the Fort Drum Army base. St. Lawrence and Lewis Counties include a number of small towns and rural areas. These three counties include a population of approximately 194,540 or 17.3 percent of the regional total.

The eastern part of the Central New York Health Service Area comprises Oneida and Herkimer Counties. Oneida County includes the City of Utica, the second largest metropolitan area in the region, the City of Rose, as well as numerous small towns and rural areas. Herkimer County includes small towns and rural areas. These two counties include a population of approximately 231,617 , or 20.6 percent of the regional total. 
Regional planning in the region was the responsibility of the Central New York Health Systems Agency under federal health planning legislation during the 1970s. After the expiration of federal health planning legislation, the Central New York Health Systems Area was supported by New York State funding for approximately 20 years.

\section{Method}

This case study evaluated hospital discharges by All Patients Refined Diagnosis Related Groups and severity of illness in the Central New York Health Service Area during 2017, the most recent time period for which complete data were available. The study was based on adult medicine and adult surgery, the inpatient services with the largest inpatient volumes. It was based on discharges for all payors.

The study was based on these hospital services as defined by the All Patients Refined Diagnosis Related Groups developed by $3 \mathrm{M}^{\mathrm{TM}}$ Health Information Systems. It was also based on the All Patients Refined Severity of Illness System. This algorithm identifies severity of illness for each hospital inpatient based on the principal diagnosis, all secondary diagnoses, and demographic indicators such as age and gender [3].

Data for the study were obtained from the New York State Planning and Research Cooperative System. These data include all discharges from New York State hospitals for residents of the State. They do not include discharges from hospitals outside the State.

The study was conducted by the Hospital Executive Council, the planning organization for the Syracuse hospitals. The Council is responsible for studies and programs that improve efficiency in the service area of the hospitals [11].

The study focused on identification of numbers of discharges and discharges by Resident County for the eleven counties in the Central New York Health Service Area. It was based on discharges for these resident populations, regardless of provider in New York State, rather than on hospital specific utilization.

Within adult medicine and adult surgery, the analysis focused on comparison of resident county populations for patients with Minor, Moderate, Major, and Extreme severity of illness. These comparisons were made with respect to numbers of discharges and percent of total discharges for each resident county.

The study also included comparison of the distribution of hospital inpatients by severity of illness between adult medicine and adult surgery. As in the analysis for individual services, percentages of total discharges were used to standardize the distributions of inpatients by severity of illness.

\section{Results}

The initial component of the case study evaluated resident adult medicine hospital discharges in the Central New York Health Service Area by severity of illness. Relevant data are summarized in Table 1. 
Table 1. Inpatient adult medicine discharges by severity of illness, Central New York Counties, 2017.

\begin{tabular}{|c|c|c|c|c|c|c|c|c|c|c|}
\hline \multirow{2}{*}{ Resident County } & \multicolumn{5}{|c|}{ Number of Discharges } & \multicolumn{5}{|c|}{ Percent of Total } \\
\hline & Minor & Moderate & Major & Extreme & Total & Minor & Moderate & Major & Extreme & Total \\
\hline Onondaga County & 3171 & 9306 & 8560 & 2253 & 23,290 & 13.62 & 39.96 & 36.75 & 9.67 & 100.00 \\
\hline Cayuga County & 484 & 1653 & 1999 & 498 & 4634 & 10.44 & 35.67 & 43.14 & 10.75 & 100.00 \\
\hline Cortland County & 338 & 956 & 1066 & 331 & 2691 & 12.56 & 35.53 & 39.61 & 12.30 & 100.00 \\
\hline Madison County & 392 & 1217 & 1059 & 238 & 2906 & 13.49 & 41.88 & 36.44 & 8.19 & 100.00 \\
\hline Oswego County & 707 & 2247 & 2351 & 803 & 6108 & 11.57 & 36.79 & 38.49 & 13.15 & 100.00 \\
\hline Tompkins County & 321 & 1074 & 1181 & 301 & 2877 & 11.16 & 37.33 & 41.05 & 10.46 & 100.00 \\
\hline Oneida County & 2183 & 6265 & 4745 & 1255 & 14,448 & 15.11 & 43.36 & 32.84 & 8.69 & 100.00 \\
\hline Herkimer County & 615 & 1665 & 1250 & 271 & 3801 & 16.18 & 43.80 & 32.89 & 7.13 & 100.00 \\
\hline Jefferson County & 730 & 2136 & 1923 & 443 & 5232 & 13.95 & 40.83 & 36.75 & 8.47 & 100.00 \\
\hline Lewis County & 196 & 606 & 431 & 80 & 1313 & 14.93 & 46.15 & 32.83 & 6.09 & 100.00 \\
\hline St. Lawrence County & 920 & 2385 & 2181 & 536 & 6022 & 15.28 & 39.60 & 36.22 & 8.90 & 100.00 \\
\hline Total & 10,057 & 29,510 & 26,746 & 7009 & 73,322 & 13.72 & 40.25 & 36.48 & 9.56 & 100.00 \\
\hline
\end{tabular}

Includes patients aged 18 years and over assigned to medical APR Diagnosis Related Groups excluding obstetrics (APR DRGs 540 - 566), mental health/substance abuse treatment (APR DRGs 740 - 776), and rehabilitation (APR DRG 860). Sources: New York Statewide Planning \& Research Cooperative System (SPARCS) data.

These data were identified by Resident County, rather than hospital specific discharges, within the Region. They were based on total numbers of resident hospital discharges for all payors and resident populations. They were developed for Minor, Moderate, Major, and Extreme severity of illness.

This information identified large differences in numbers of resident inpatient discharges among the Central New York Counties in 2017. The two metropolitan areas, Onondaga and Oneida Counties, generated the largest numbers of discharges. Largely rural counties such as Cortland, Madison, and Lewis produced considerably smaller numbers.

In contrast, the data indicated that variation among percentages of adult medicine patients within each of the four severity of illness categories among counties in the Central New York Health Service Area was relatively limited. The largest proportions were generated by Major severity, ranging from 32 to 43 percent and Moderate severity, from 35 to 46 percent.

The lowest and highest levels of severity accounted for much smaller proportions of total discharges among Central New York counties. Patients at Minor severity of illness accounted for $10-16$ percent and those at Extreme severity were responsible for 6 - 13 percent. These data suggested that for adult medicine discharges, outlier patients with low and high severity were a small minority of the total resident population.

The study also included a review of resident hospital lengths of stay by severity of illness for each of the eleven counties in the region. For ten of the eleven counties, the lengths of stay increased for each severity of illness category compared with the one before. 
The second component of the case study evaluated resident adult surgery discharges in the Central New York Health Service Area by severity of illness. Relevant data are summarized in Table 2 .

As in the case of adult medicine, these data identified substantial differences in numbers of resident discharges among Central New York Counties in 2017. The largest numbers were generated by Onondaga County, including Syracuse, and Oneida County, including Utica. The smallest numbers of discharges were produced by largely rural counties such as Cortland and Lewis.

The data indicated that variations in percentages of total discharges for individual levels of severity among Central New York counties were limited. The largest percentages among the counties were produced by Moderate severity, 35 - 42 percent of the total, and Minor severity, 31 - 41 percent. Smaller percentages were produced by Major severity, 15 - 18 percent, and Extreme severity, 5 - 10 percent.

In comparison with the severity of illness data for adult medicine, the adult surgery data included a substantial increase for Minor severity of illness patients in the Central New York Health Service Area. Patients in this category accounted for 31 - 41 percent of the adult surgery population, compared with 10 16 percent of the adult medicine population. The percent of total patients at Moderate severity of illness was almost the same for the two services, 35 to 46 percent for adult medicine and $35-42$ percent for adult surgery.

A follow up analysis identified two All Patients Refined Major Diagnostic Categories (APR MDC) that contributed to the differences, Orthopedics (APR MDC 8) and Nutritional and Metabolic (APR MDC 10). In Orthopedics, the number of Minor severity resident discharges was 5462 for adult surgery and 542

Table 2. Inpatient adult surgery discharges by severity of illness, Central New York Counties, 2017.

\begin{tabular}{|c|c|c|c|c|c|c|c|c|c|c|}
\hline \multirow{2}{*}{ Resident County } & \multicolumn{5}{|c|}{ Number of Discharges } & \multicolumn{5}{|c|}{ Percent of Total } \\
\hline & Minor & Moderate & Major & Extreme & Total & Minor & Moderate & Major & Extreme & Total \\
\hline Onondaga County & 4151 & 4318 & 1960 & 916 & 11,345 & 36.59 & 38.06 & 17.28 & 8.07 & 100.00 \\
\hline Cayuga County & 526 & 635 & 277 & 116 & 1554 & 33.85 & 40.86 & 17.82 & 7.46 & 100.00 \\
\hline Cortland County & 343 & 432 & 203 & 120 & 1098 & 31.24 & 39.34 & 18.49 & 10.93 & 100.00 \\
\hline Madison County & 670 & 649 & 275 & 104 & 1698 & 39.46 & 38.22 & 16.20 & 6.12 & 100.00 \\
\hline Oswego County & 1111 & 1326 & 565 & 237 & 3239 & 34.30 & 40.94 & 17.44 & 7.32 & 100.00 \\
\hline Tompkins County & 465 & 571 & 205 & 101 & 1342 & 34.65 & 42.55 & 15.28 & 7.53 & 100.00 \\
\hline Oneida County & 2881 & 2568 & 1079 & 479 & 7007 & 41.12 & 36.65 & 15.40 & 6.84 & 100.00 \\
\hline Herkimer County & 649 & 571 & 297 & 113 & 1630 & 39.82 & 35.03 & 18.22 & 6.93 & 100.00 \\
\hline Jefferson County & 985 & 888 & 431 & 171 & 2475 & 39.80 & 35.88 & 17.41 & 6.91 & 100.00 \\
\hline Lewis County & 247 & 223 & 92 & 47 & 609 & 40.56 & 36.62 & 15.11 & 7.72 & 100.00 \\
\hline St. Lawrence County & 745 & 865 & 366 & 109 & 2085 & 35.73 & 41.49 & 17.55 & 5.23 & 100.00 \\
\hline Total & 12,773 & 13,046 & 5750 & 2513 & 34,082 & 37.48 & 38.28 & 16.87 & 7.37 & 100.00 \\
\hline
\end{tabular}

Includes patients aged 18 years and over assigned to surgical APR Diagnosis Related Groups excluding obstetrics (APR DRGs 540 - 566) and mental health/substance abuse treatment (APR DRGs 740 - 776). Sources: New York Statewide Planning \& Research Cooperative System (SPARCS) data. 
for adult medicine. This difference was produced by joint procedures such as hip and knee replacements. In APR MDC 10, the comparison was 1123 resident discharges for adult surgery and 350 for adult medicine. The difference was produced by operating room procedures for obesity.

The study also included a review of resident hospital lengths of stay by severity of illness for each of the eleven counties in the region. For all of the eleven counties, the lengths of stay increased for each severity of illness category compared with the one before.

\section{Discussion}

During the 1970s and 1980s, government sponsored health planning in the United States focused attention on population-based use of services. Since that time, attention has shifted to provider specific utilization including severity of illness and other clinical indicators.

This case study evaluated the impact of severity of illness for hospital patients in the Central New York Health Service Area, one of the original health planning populations. It analyzed the impact of severity within resident populations, rather than by individual providers.

The study data demonstrated that patients at Extreme severity of illness, the highest level, constituted similar proportions of adult medicine, 6 - 13 percent, and adult surgery, 5 - 10 percent, in the eleven county region. This information suggested that the sizes of these outlier populations were similar. The data also suggested that the sizes of Moderate severity populations in the two services were similar, 35 - 46 percent in adult medicine and 35 - 42 percent in adult surgery.

The study data identified considerable differences in the sizes of Minor and Major severity of illness resident populations for the two services across the eleven county region. Patients at Minor severity accounted for $10-16$ percent of adult medicine and $31-41$ percent of adult surgery resident populations. Patients at Major severity accounted for 32 - 43 percent of adult medicine and 15 18 percent of adult surgery resident populations.

These differences resulted from large numbers of healthy patients in the adult surgery resident populations. Most of these inpatients were admitted for orthopedic procedures such as joint replacements and procedures to address obesity.

This analysis addressed the distribution of resident hospital inpatients by severity of illness in a single Health Service Area. Additional research, related to population health, should evaluate these indicators in additional health planning regions.

\section{Conflicts of Interest}

The authors declare that they have no conflict of interest.

\section{References}

[1] Chassin, M.R., Brook, R.H., Park, R.E., Kessey, J., Fink, A., Kahn, K., Merrick, N. 
and Solomon, D.H. (1986) Variations in the Use of Medical and Surgical Services by the Medicaid Population. New England Journal of Medicine, 315, 285-290. https://doi.org/10.1056/NEJM198601303140505

[2] Tedesch, P.I., Wolfe, R.A. and Griffith, J.R. (1990) Micro Area Variation in Hospital Use. Health Services Research, 24, 729-740.

[3] Hyman, H.H. (1982) Health Planning: A Systematic Approach. Oxford Publishing, London.

[4] Dentzler, S. (2011) Urgent Measures for an Old Problem. Health Affairs, 30, 1626. https://doi.org/10.1377/hlthaff.2011.0961

[5] $3 \mathrm{M}^{\mathrm{TM}}$ Health Information Systems (1998) All Patients Refined Diagnosis Related Groups (APR-DRGs). Wallingford.

[6] Hasselman, D. (2013) Super Utilizer Summit: Common Themes from Innovative Complex Care Management. Center for Health Strategies, Princeton, NJ.

[7] Hong, C.S., Siegel, A.L. and Ferris, T.G. (2014) Caring for High Need, High Cost Patients: What Makes for a Successful Program. Commonwealth Fund, New York.

[8] Barr, P. (2015) Three Practical Approaches to Population Health. Hospitals and Health Networks, 89, 22-27.

[9] Goldfield, N., McCullough, E.C., Hughes, J.S., Tang, A.M., Eastman, B., Rawlins, L.K. and Averill, R.F. (2009) Identifying Potentially Preventable Readmissions. Health Care Financing Review, 30, 75-92.

[10] Central New York Health Systems Agency (1979) Program Implementation Plan. CNYHSA, Dewitt, NY.

[11] Lagoe, R., Pasinski, T., Kronenberg, P., Quinn, T. and Schaengold, P. (2006) Linking Health Services at the Community Level. Canada Health Care Quarterly, 9, 60-65. 